\title{
Traffic Safety Improvement and the Role of GIS (A Case Study of Karachi, Pakistan)
}

\author{
Muhammad Asim Azim ${ }^{1}$, Zhai Fengwen², Dang Jianwu ${ }^{3}$, Yan Haowen ${ }^{4}$, Miss \\ Wang yang ${ }^{5}$ \\ School of Electronic and Information Engineering, Lanzhou Jiaotong University, P.R. China
}

\begin{abstract}
Traffic safety problems are most significant issues all around the world, but out of the ordinary for developing countries, as 90\% occurrences happened in these regions. Karachi is the capital of Sindh province and it was the capital of Pakistan during 1947-59 before being replaced by Islamabad. So Karachi considered as vital city of Pakistan due to geo graphic location and different attributes such as population, economy, road networks, sea port and industries to give the impression of being all state of affairs including safety threat become considerable issue in Karachi, Pakistan. In this paper, improvement is center of attention all through in presence situation, polices related problem and call attention GIS contribution. There are necessary a lot of things for doing to emphasize better safety but not including substantial tribulations make known to become in control. By using SPSS and Pivot Table (in excel), easy draw attention to complete situation and here Geographic Information System (GIS) appropriately classify areas as a result of first three highest abnormal numbers of causalities
\end{abstract}

Keywords - Road Traffic Causalities, Statistical Package of Social Science, Geographic Information System, Karachi, Pakistan

\section{Introduction}

Due to lack of traffic safety system, approximately 1.2 million people die and 50 million injured every year in the world. In light of the World Bank report the figure arise to 65\% during year 2000 to 2020 (WHO 2004). This is the reason traffic safety and its management is a key problem in world, mainly significant for developing countries because of $90 \%$ occurrence happened here. Our research domain is towards Pakistan safety Crisis. In comparison of the population, Pakistan is in seventh number in south Asia and at sixth in entire world (approximately 170 million by reported 2011 Population census). Whereas Karachi is a Mega city with a population of 20 million people.

Pakistan suffers 100 billion rupees, in maintenance side due to lack of traffic safety. Karachi is the most vital city of Pakistan with a huge population, economic potential and geo-strategic location [1]. The per capita income in Pakistan is very low, even more then $70 \%$ people earn $\$ 2$ per a day. Most of the families are dependent to one bread winner, so it very easy to judge the value of that individual in a family. No doubt the roads conditions in Pakistan are not so poor, but the lack of safety precautions is a cause of major hazards. Therefore we should have to consider those elements that protect and save the life of the peoples, and provide safe movement to obstruct the maximum threat. According to the Asian Development Bank 2007 the projected economic losses are at least $2 \%$.

Ministry of communication MOC works under Federal level and Transport Research Centre NTRC works under MOC in Pakistan. These institutions facilitate the decision makers to improve the transportation structure of the country. While provincial and district authorities are responsible for pursue the policies from MOC. In 1998 these institutes update their rules and regulations but ministries do not reply them. So with the support of World Bank, National Transport policies were imposed at provincial level after 2000. Also task was re-assigned to NTRC by MOC. Here we face another issue, the lack of capacity and economic barrier. Because of these issues NTRC could not organized policies, which also does not acceptable by government. In the mid of 2004, Asian development Bank ADB provide a support in the form of economic and technical assistance, then in 2008 drafted transport policy also known as Technical Assistance competition Report TA is implemented with the approval of government of Pakistan. In 2006 road traffic injury research and prevention center was established by federal ministry of health, Govt. of Pakistan, with the pool resources of Jinnah postgraduate Medical Center, Karachi. An increase in sales of vehicles and increment of liberalization in Karachi road injury surveillance project was started. The main principal of these programs was to maintain Road traffic Injury and research with the support of policy technocrats. Furthermore, from 2006 to onward RTIPC maintain data from five main emergency centers at city including three government hospitals. Also this data is taken from other sources, like ambulance, newspaper, agencies, mortuaries, police and victims themselves.[2]. However in data bank field, Federal Ministry of Health build huge endeavor but still there have no big ability all through seem to be in security danger, due to institutional fence in country. The basic problem in traffic security system is 
financial problem, but if national level policies are organized in a well-mannered in view of geo graphics urban region, then effortlessly overcomes these threats. For the purpose we just need to focus on the central factors.

\section{Methodology}

We conform on three year (2009-2011) preliminary data from Road Traffic injury and prevention center (RTI\&PC) Karachi, Pakistan [6], contributory data related to find out three years situation, at least it will help out to find ratio probably changing by year wise. After to ensure analysis in SPSS ratio between three years be clear respectively 32-34 \% as shown in Figure 1, meanwhile, situation according to see result as predicted very dangerous.

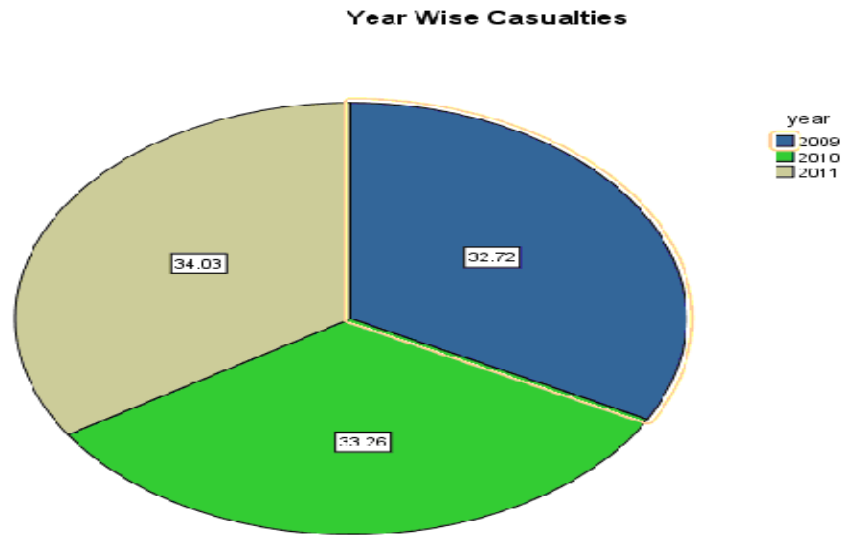

Fig.1. (Statistical Analysis using SPSS)

Although to see last three years evolution, there is no big achievement in safety related work and not take as seriously for its improvement. If there is no big achievement so its means safety condition not become in control. After ensure situation, in second step we try to find out either if situation goes like this way what happened in future, so we utilize prediction technique (in excel) to find out results why safety improvements are necessary to give the impression of being present order, as shown Fig no 2.

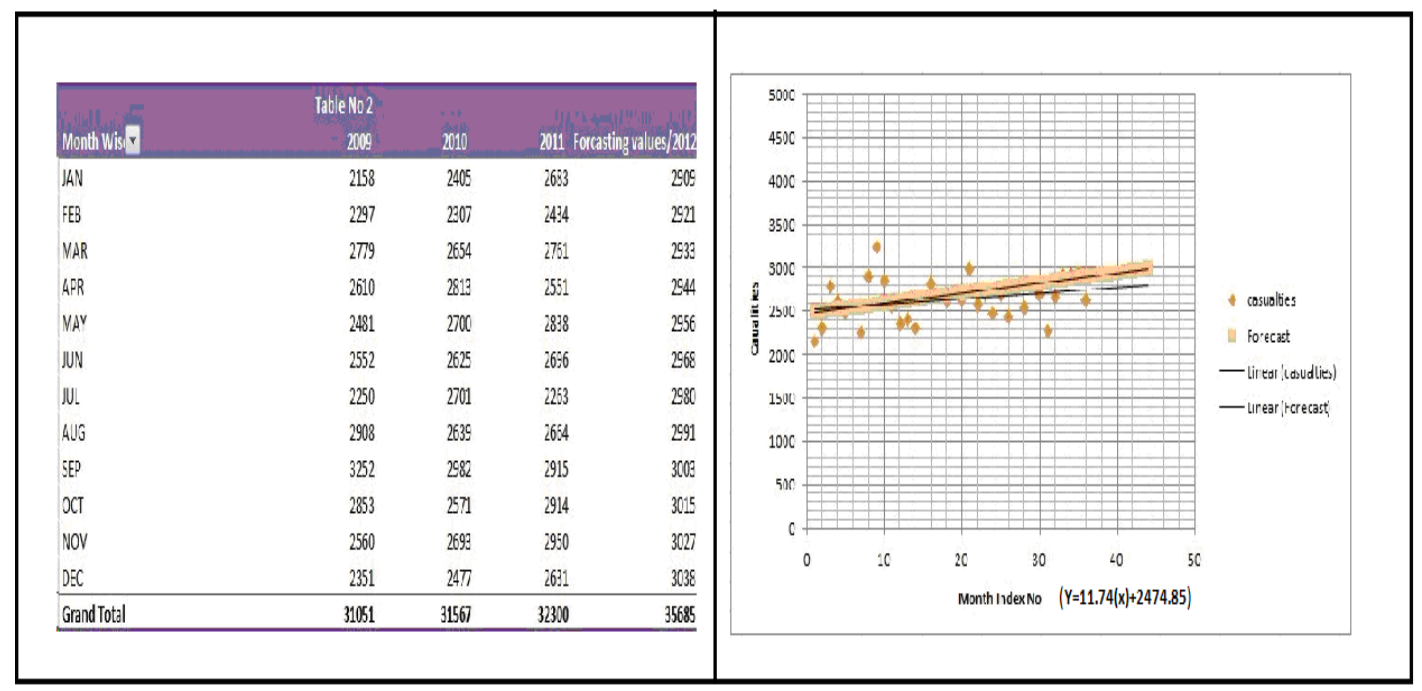

Fig. 2. (Influence at Entire protection)

Subsequent to conformation last three year progress (2009-11) and make out future based results, no doubt there is no big achievement to reduce threat in entire traffic safety or improvements. At third rung, in favor of identify causal issues we take assessment on last year 2011, hazard data and examine all causative issues that have involvement to create threat in protection structure and categorize all causative issues with revere to its causalities. After analyzing it turn out to be easier to appreciate that new policy be able to relate with maximum threat. The analysis data and injudicious actions is a main factor, have $47 \%$ ( 47 percent by Total) influences at entire protection system. As future examination. There are a lot of reasons to grow up injudicious action but further examination of injudicious action can play supplementary role as improvement of 
traffic safety because after examination uncomplicated to identify problem related policy. By analyzing we found that injudicious actions are caused by over speed. At this time, it become very easy to realize for policy maker's that make policies to look real threat, as show in figure 3 .

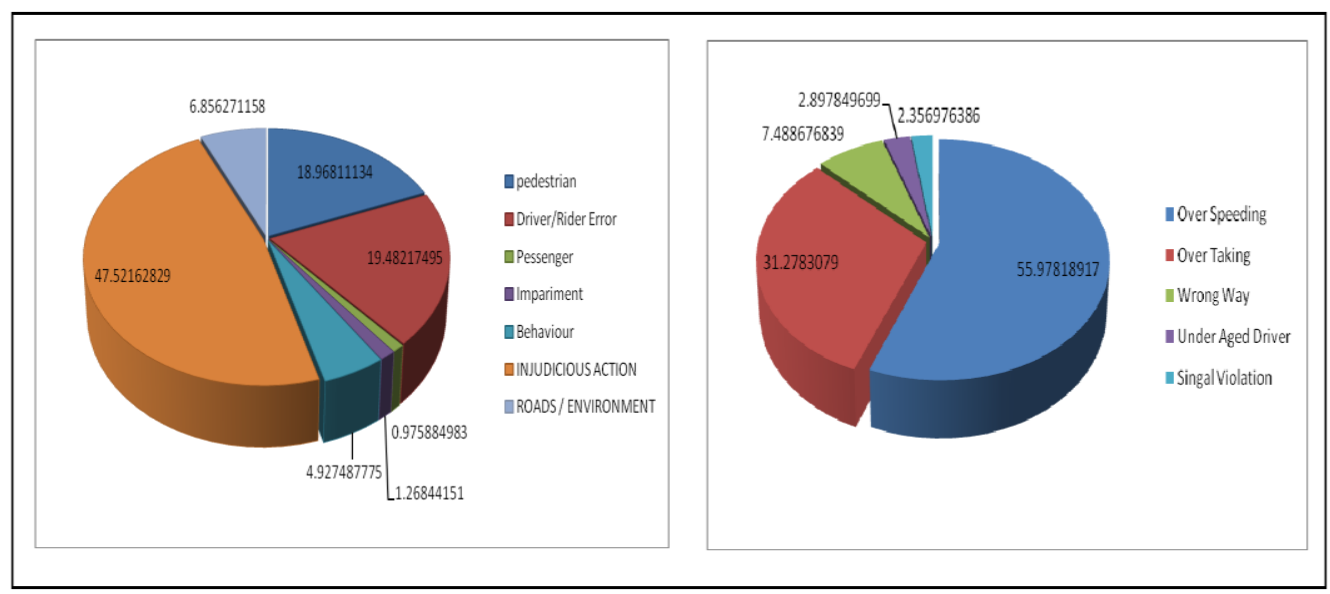

Fig. 3. (Factors influence on Safety precautions)

\section{Role of GIS in safety Improvements}

Before discussing about GIS system and its role in transportation system we need to know about the geographic condition of our focused area

\subsection{Geographic condition of Karachi, Pakistan}

Karachi is the capital of Sindh province and spread over 3,527 sq. kilometers but Karachi urban area spread over nearly 1800 sq. kilometers (700 sq. miles or 444,800 acres approximately). Basically Karachi is divided into 18 towns and six cantonments boards and different other agencies. It is amongst the fifteen biggest cities in the world, for the reason that population of Karachi estimated to be close 20 million (2012). Outstanding geographic condition Karachi considered as mage city of Pakistan and huge part of economy contributes from here, Figure 4 shows the Fact-Box of Karachi, Pakistan.

\begin{tabular}{|c|c|}
\hline \multicolumn{2}{|c|}{$F A C T-B O X$} \\
\hline Province & Sindh \\
\hline Location & karachi \\
\hline Altatude & $26 \mathrm{ft}$ \\
\hline Area & $3.527 \mathrm{~km}^{2}$ \\
\hline Density & 15,500 per square mille \\
\hline Calling code & 021 \\
\hline Time zone & $\begin{array}{c}\text { PST + OS:OO shead of } \\
\text { GMT }\end{array}$ \\
\hline No. of Towins & 18 \\
\hline $\begin{array}{l}\text { No. of Union } \\
\text { Councils }\end{array}$ & 178 \\
\hline No. of & 06 \\
\hline $\begin{array}{l}\text { City Mayor } \\
\text { (Narim) }\end{array}$ & Mustata Kamal \\
\hline \multicolumn{2}{|l|}{ POPULATION } \\
\hline Census (1998) & 9856318 persons \\
\hline Estimate (2006) & 17.5 -million \\
\hline
\end{tabular}

Fig. 4. (Fact Box)

\subsection{Featured Study}

Transportation based Geographic Information System (GIS) study called as GIS-T (Miller and Shaw, 2001). Latter on 1980s, GIS turn into vital element of transportation examine area (Thill, 2000) specially in safety study [5]. GIS is also used in safety application for developing transportation systems [6]. However, different researchers use different techniques to augment safety $(3,4,6-8)$ in GIS system. Three most significant functions of GIS in road traffic safety are:

- Extensively use of GIS in diversity of application for setting up, making better verdict and revelation.

- Provide the facility as databank source

- GIS provide the facility to organize and centralized data in Management prospective. 
Before any improvements GIS can provide the facility to researcher to analyze huge threat areas for better conclusion and geographic acquaintance related HTL. This is why policy maker mainly focus on GIS and take as case study area for better expansion.

In this case, give the impression of being GIS in improvements already done by RTI\&PC in 2011 and declare there are main three high threat arterials that have far above the ground numbers of causalities. All irregular causalities are classified from first to last as special distribution of town wise causalities but first three are very important to seem threat for intensions because there safety agencies are facing immense challenges. In order to seem results role of GIS in safety improvements become more clear and provide the plat form to take as case study for better decisions specially polices related decisions.

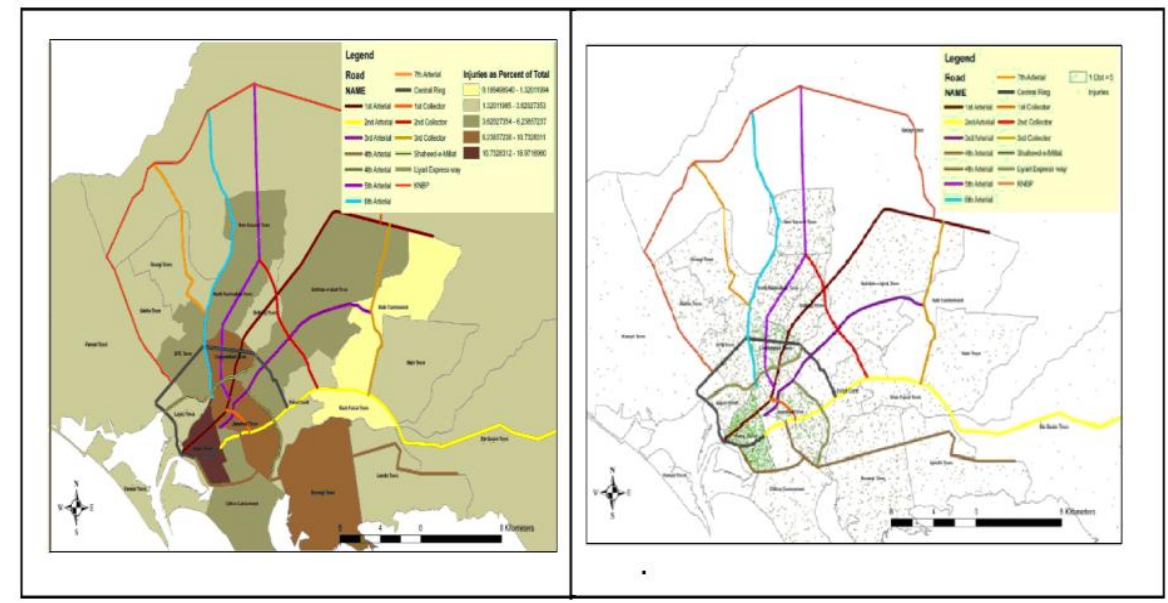

Fig. 5. (Map published at RTIR \& PC yearly description [under, exhibit 1.56 \& 1.57)

The map shows the fatalities as a proportion of overall victims report in Karachi, That shows the, Saddar town has the highest casualty rate followed by Jamshed town, and Liaquatabad town (RTIPC,2009, exhibit $1.56 \& 1.57$ ) as shown Figure 5.

Although after statistical analysis, there are no big achievements in during 2009-11 related to improvements because the numbers of causalities are increased respectively year wise in Saddar town, Jamshed town and Liaquatabad town but all the way through GIS and it's applications data can visualize very easy to understand emerging situation. There is no doubt further improvements in traffic safety can be relate with GIS and its applications.

\section{Conclusion and Recommendations}

This research can be used to high light those factors that have major contribution to increased threat in traffic safety and strongly recommended that there are required at emergency bases some initiatives, meanwhile target lifesaving and strategy for efficient policies. In conclusion, an injudicious action is a one big reason that has $47 \%$ influences in entire traffic safety. No doubt there are also other important reasons but injudicious actions is one of them. If safety agencies or departments prepare policy draft after acknowledged actual situation step by step in priority bases then situation can become in control. After statistical analysis, during examination period total threat increased $1 \%$ by yearly (2009-2011) but if situation stands like this then according to predictive values, threat increased dramatically more than $1 \%$ by yearly and causalities can be cross 3000 per month because there is no effective policies for impede injudicious actions. Regulatory bodies must concerned those relatives polices that plays leading role to impede threats through awareness and strict punishment for over speeding, overtaking, under aged drivers, wrong way and signal violation. Karachi is famed city amongst cities all around world due to geo-graphic location, population, sea port, education and industries comparatively other cities of Pakistan so most of Pakistani community likes to move there for good future. Author strongly believes that urgent initiatives for injudicious actions contribute in traffic safety improvement. In this case, give the impression of being GIS in improvements already done by RTI\&PC and declare there are main three high threat arterials (in Saddar,Liaquatabad and Jamshed Town) that have far above the ground numbers of causalities. All irregular causalities are classified from first to last as special distribution of town wise causalities but first three are very important to seem threat for intensions because there safety agencies are facing immense challenges. In order to seem results role of GIS in safety improvements become more clear and provide the plat form to take as case study for better decisions specially polices related decisions. 
[1]. J. Geogr. Regional Plan., vol. 3, no. 11, pp. 306-321,2010.

[2]. Razzak, J. A. and Luby, S. P., 1998. Estimating deaths and injuries due to road traffic accidents in Karachi, Pakistan, through the capture-recapture method. International Journal of Epidemiology 27, 866-870.

[3]. Levine, N., K. Kim, and L. Nitz. Spatial analysis of Honolulu motor vehicle crashes: part II: zonal predictions, Accident Analysis and Prevention, Vol. 27, No.5, 1995, pp. 675-685.

[4]. Affum, J. K., and M. A. P. Taylor. Technology tools for transportation professionals - moving into the 21st century: Resource papers for the 1995 International conference, Integrated GIS database for road safety management. Institute of Transportation Engineers, Washington, D.C., 1995, pp.189-193.

[5]. Austin, K., M. Tight, and H. Kirby. The use of geographical information systems to enhance road safety analysis, Transportation Planning andTechnology, Vol. 20, No. 4, 1997, pp. 249-266.

[6]. Kim, K., and N. Levine. Using GIS to improve highway safety, Computers, Environment and Urban Systems, Vol. 20, No. 4, 1996, pp. 289-302.

[7]. Miller, J. S. What value may geographic information systems add to the art of identifying crash countermeasures?, Report VTRC 99-R13, 1999

[8]. Pulugurtha, S. S., V. K. Krishnakumar, and S. S. Nambisan. New methods to identify and rank high pedestrian crash zones: An illustration, Accident Analysis and Prevention, Vol. 39, No. 4, 2007, pp. 800-811.

[9]. FIA Foundation for the Automobile and Society. Seat Belt Campaign Toolkit. TRL Limited. http://www.fiafoundation.com/resources/documents/559466302_toolkit.pdf Retrieved at 18/06/07

[10]. Liberatti et al. The new Brazilian traffic code and some characteristics of victims in southern Brazil.Inj Prev. 2001 Sep;7(3):190-3.

[11]. Liberatti et al. The new Brazilian traffic code and some characteristics of victims in southern Brazil.Inj Prev. 2001 Sep;7(3):190-3.

[12]. Evelio et al. Use of suitable helmet and its relation with maxillofacial and skull fractures in motorcyclists in Cali, Colombia. DOAJ - Directory of Open Access Journals, Year: 2004 Volume: 35 - Issue: 3 Supl 1

[13]. FIA Foundation for the Automobile and Society. Costa Rica's Seat Belt Campaign. http://www.fiafoundation.com/resources/documents/1455606842_por_amor.pdf Retrieved at 20/6/07

[14]. Crandon et al. The prevalence of seat belt use in Kingston, Jamaica: a follow-up observational study five years after the introduction of legislation. 1: West Indian Med J. 2006 Oct;55(5):327-9.
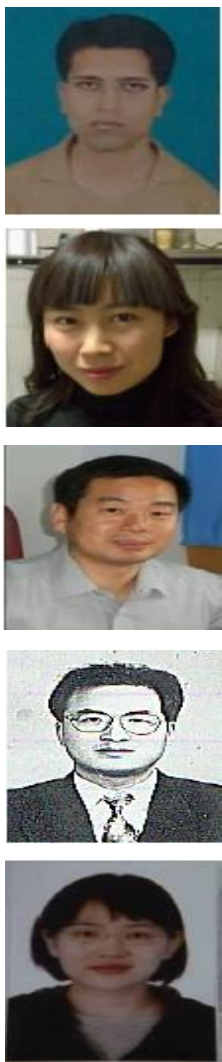

Muhammad Asim Azim is a Doctorate student in School of Electronics and Information Engineering, Lanzhou Jiaotong University, Gansu, China form 2011.He completed his Master degree in Telecommunication from Preston University, Pakistan in 2009. His current Interests to address Transportation related Safety issues to Utilize GIS \& Its applications.

Fengwen Zhai was born in 1980. She received her MSc degree in computer technology and application in 2003 from Jilin University. She is currently a PhD candidate in School of Electronic \& Information Engineering, Lanzhou Jiaotong University. Her main interests include intelligent information processing and image processing.

Jianwu Dang was born in 1963. He received his MSc degree in 1992 and his $\mathrm{PhD}$ degree in 1996 from South west Jiaotong University. He is currently a professor and $\mathrm{PhD}$ supervisor in School of Electronic \& Information Engineering, Lanzhou Jiaotong University. His main research interests include intelligent information processing and. Neural networks.

Haowen YAN is a professor of Geographic Information Science with Lanzhou Jiaotong University. He holds Bachelor's, Master's and Doctor's degrees in Cartography and Geographic Information Engineering from Wuhan University, China. His research interests lie in theories of spatial relation and automated map generalization.

Yangping Wang received her MSc degree in computer technology and application from Lanzhou Jiaotong University. She received PhD degree in the same University in 2010. She had been a visiting scholar at the University of Queensland, Australia from August 2008 to August 2009. Now she is an associate professor in Lanzhou Jiaotong University and her research interests focus on medical image processing and intelligent information processing . 